\title{
Oral Manifestations of Neurofibromatosis Type 1
}

\author{
Hafida Cherifi'1,2, Benjamin Fournier2,3, Ariane Berdal2,3, \\ Blake McAlpin ${ }^{4}$, Ishaï-Yaacov Sitbon ${ }^{1}$, Bruno Gogly ${ }^{1,2 *}$
}

\author{
${ }^{1}$ Henri Mondor Hospital, Dental Department, Paris Descartes University, Paris, France \\ ${ }^{2}$ Laboratory of Molecular Oral Pathophysiology, Paris, France \\ ${ }^{3}$ Rotschild Hospital, Centre de référence MAFACE, Paris Diderot University, Paris, France \\ ${ }^{4}$ Neuroimmunology Laboratory, Department of Symptom Research, Division of Internal Medicine, \\ University of Texas MD Anderson Cancer Center, Houston, USA \\ Email: *brunogogly77@gmail.com
}

How to cite this paper: Cherifi, H., Fournier, B., Berdal, A., McAlpin, B., Sitbon, I.-Y. and Gogly, B. (2019) Oral Manifestations of Neurofibromatosis Type 1. Journal of Cosmetics, Dermatological Sciences and Applications, 9, 41-55.

https://doi.org/10.4236/jcdsa.2019.91004

Received: January 10, 2019

Accepted: February 15, 2019

Published: February 18, 2019

Copyright $\odot 2019$ by author(s) and Scientific Research Publishing Inc. This work is licensed under the Creative Commons Attribution International License (CC BY 4.0).

http://creativecommons.org/licenses/by/4.0/

\begin{abstract}
Neurofibromatosis type 1 (NF-1) is a common genetic disorder with a highly variable phenotype. The disease affects both proliferation and differentiation of cells of neurectodermal origin. The presence of tumors is very common like benign nodular neurofibromas. Tumors with unclear prognosis may be present like plexiform neurofibromas whose prognosis is more uncertain. While many organs exhibit pathologies, most commonly affected are the nervous system, skin, gastrointestinal tract and heart. Oral abnormalities are also very common: $72 \%$ of NF-1 patients exhibit pathologies in oral mucosa, gums, maxillary and temporomandibular joints, and teeth. The incidence of NF-1 and its relationship to the prevalence of caries have been discussed in other researches. It is known that poor oral hygiene plays a key role in the development of periodontal disease and caries. Here we review the oral manifestations of neurofibromatosis type 1 that we illustrate by a patient followed in the center of rare diseases of the hospital Henri Mondor, clinical service in which we work.
\end{abstract}

\section{Keywords}

Neurofibromatosis Type 1, Genetic Disorder, Oral Tumor, Jaw Abnormalities, Periodontal Disease

\section{Introduction}

Neurofibromatosis (NF) is a genetic disorder that disrupts the nervous system. It affects preferentially tissues derived from the neural crest [1]. In 1982, Riccardi 
proposed a classification system for seven different types of NF and an additional grouping of non-classifiable NF [1]. Among these classes, two have been the most well-established: neurofibromatosis type 1 (NF-1, OMIM \#162200), also called Recklinghausen disease, and neurofibromatosis type 2 (NF-2, OMIM \#101000), which affect the central nervous system. The more common of the two, NF-1, was first described by Friedrich Daniel Recklinghausen in 1882. NF-1 is an autosomal dominant genetic disorder that affects 1 birth in 3000; regardless of gender or race [2] [3], it is caused by mutation of the NF1 gene. In $50 \%$ of cases the disease is caused by spontaneous mutation with no family history of NF [4]. NF1 is a tumor-suppressor gene located on the long arm of chromosome 17, in the pericentromeric region at position 11.2 (17q11.2). The gene extends over about 350 kilobases with 57 constitutive exons and 3 alternative exons. Here we describe the structure of the gene involved in the pathology. The NF1 gene can be mutated in several ways either as a deletion, insertion, nonsense or missense mutation [5] [6]. The different mutations result in different clinical situations [7]. The gene product is Neurofibromin which is a $220 \mathrm{kDa}$ cytoplasmic protein of 2818 amino acids belonging to the GTPase Activating Protein (GAP) family protein. Indeed, there is a 360 amino acids domain corresponding to a GAP related domain (GRD). The protein produced by the abnormal NF1 gene of neurofibromatosis is therefore neurofibromin. Neurofibromin is produced by many cell types, particularly by neurons and neuroglia (oligodendrocytes and Schwann cells) and epidermal cells (keratinocytes and melanocytes) [8] [9]. It inhibits the ras signal transduction pathway via negative regulation of a ras GTPase and thus controls cell growth [10] [11]. Neurofibromin signaling induces the transformation of the active form, p21 ras-GTP, to the inactive form, p21 ras-GDP. The tumor-suppressing function of neurofibromin is achieved via this regulation of active and inactive forms of p21ras. Thus, mutations in NF1 inhibit its tumor-suppressing function and lead to tumor formation. These tumors are characteristic of NF1. However, in some cases of NF-1 patients, no mutations were detected. There may be a disorder in the RNA maturation in the splicing. The pathology of NF-1 is different depending on NF1 mRNA editing [12]. Four different isoforms of NF1 gene have been described; the two most well-known are isoform 1 (GRD1) and isoform 2 (GRD2). Their mRNAs differ by the alternate splicing of a single exon of 63 bp [13]: GRD2 has 21 additional amino-acids in the GRD domain comparatively with GRD1. These two isoforms have a significantly similar distribution throughout tissues. Isoform 3, which differs from the isoform 1 by the presence of 18 additional amino acids in the C-Terminal, is present almost exclusively in cardiac, smooth and skeletal muscle tissue [14]. Isoform 4 contains 10 more amino acids than isoform 1 and is mainly located in the central nervous system [14]. It has been demonstrated that a change from isoform 1 to isoform 2 expression may be involved in neurectodermal differentiation. The presence of the additional 21 amino acids changes the hydrophobicity and secondary structure of the GRD region [15]. Therefore, alternative splic- 
ing disorders may be related to tumor formation. The 4 isoforms of the NF1 gene are therefore the target of numerous genetic anomalies and the highly variable clinical feature may also be due to aberration affecting the NF1 mRNA mature editing process [16].

\section{Diagnosis}

Neurofibromatosis type 1 is diagnosed based on clinical criteria established by the National Institute of Health (NIH) Consensus Development Conference in 1987 (Table 1) [17] and updated in 1997 [18]. In addition, members of the United Kingdom Neurofibromatosis Association Clinical Advisory Board collaborated to produce a consensus statement on the current guidelines for the diagnosis and management of NF-1 [19]. Genetic testing is inconsistent. The phenotype/genotype correlation is difficult to establish, but patients with a microdeletion affecting the entire NF1 gene have a severe phenotype with recognizable clinical criteria [20]. This subpopulation develops neurofibromas at an earlier age, have more craniofacial deformities sometimes accompanied with a decreased IQ, and develop malignant nerve-sheat tumors [21] [22] [23]. For other NF-1 patients, the signs may be less profound, but enough to diagnose the disease (Table 1). In addition, neurofibromatosis is a neurocristopathy: Neural crest cells and the tissues that arise from them exhibit defects in development [24]. Since the oral cavity is derived from the neural crest [25], patients with neurofibromatosis type 1 typically exhibit oral disease. In fact, Shapiro et al. found that $72 \%$ of NF-1 patients exhibited oral deformities $(n=22)$ [26].

The objective of this review is to analyze the literature regarding oral manifestations in neurofibromatosis type 1, specifically oral epidermis and mucosa involvement, periodontal pathology, maxillary bone and joint lesions, dental disease and deformities, and salivation flow defects. These oral clinical

Table 1. National Institute of Health consensus criteria for diagnosis of neurofibromatosis type 1 . Neurofibromatosis type 1 is diagnosed based on clinical criteria established by the National Institute of Health (NIH) Consensus Development Conference in 1987 (Table 1) [17] and updated in 1997 [18].

Two or more of the following clinical features are sufficient to establish a diagnosis of neurofibromatosis type 1 :

\footnotetext{
- Six or morecafé-au-lait macules

$>5 \mathrm{~mm}$ diameter at the largest diameter children

$>15 \mathrm{~mm}$ diameter in post-pubescent individuals

- Axillary freckling or freckling in inguinal regions

- Two or more neurofibromas of any type or one or more plexiform neurofibromas

- Two or more Lisch nodules

- Bonelesion with sphenoid bonedysplasia or thickening of the cortex of the long bones with or without pseudoarthrosis

- An optic pathway glioma

- A first-degree relative with neurofibromatosis type 1 diagnosed by the above criteria
} 
signs are either specific to the pathology (café-au-lait-macules and neurofibromas) or they are at the origin of nonspecific but consecutive pathologies of the disease (periodontitis, dental caries, dental inclusions, variation of the salivary flow). This is detailed in the chapters below.

\section{Oro-Facial Dermal Involvement}

Café-au-lait macules are well-defined skin pigmentations whose diameter is between 5 and $50 \mathrm{~mm}$. In NF-1 patients, they can manifest in the facial area (Figure 1(b)) and trunk, particularly lateral abdomen (Figure 1(a)), with the lateral abdomen macules being typically larger. Café-au-lait macules are well-defined skin pigmentations whose diameter is between 5 and $50 \mathrm{~mm}$. In NF-1 patients, they can manifest in trunk, particularly lateral abdomen (Figure 1(a)), and in the facial area (Figure 1(b)). NF-1 patients often exhibit freckles on the oro-facial epidermis, defined as small macules of 1 to $3 \mathrm{~mm}$ spread over the skin (Figure 1(b)). They appear in childhood in $90 \%$ of cases beginning around the age of seven-years-old. They typically localize in the underarm, and more often in the inguinal folds. These hyperpigmentation macules are strongly correlated to NF-1 presence, especially when patients exhibit 6 or more macules of $15 \mathrm{~mm}$ in adults and $5 \mathrm{~mm}$ in children. Such macules are also present in other diseases such as Leopard Syndrome or McCune-Albright Syndrome. Histologically, they are related to basal keratinocyte and melanocyte hyperpigmentation that is caused by presence of numerous giant melanosomes, "macromelanosomes" [27] [28]. Indeed melanogenesis may be disrupted in NF-1 patients [29]. The cause is likely not linked to the Ras activity in melanocytes, but rather to fibroblasts activity. Here, fibroblasts are thought to overproduce Hepatocyte Growth Factor (HGF) and Stem Cell Factor (SCF), affecting epidermal melanocytes [29]. Both freckles and café-au-lait spots do not necessarily cause complications [19]. In

(a)

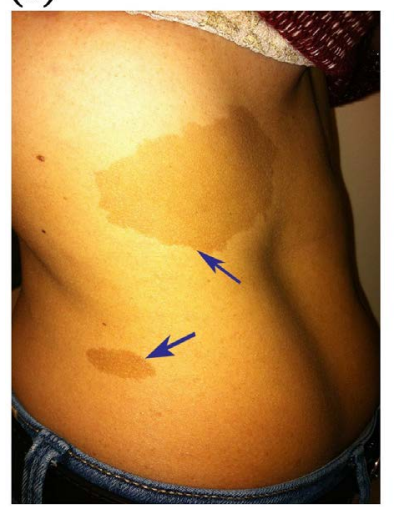

(b)

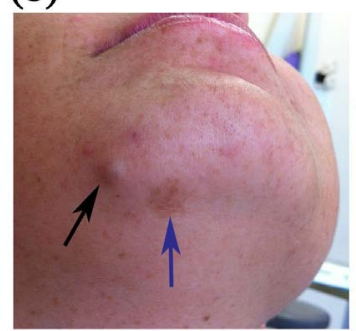

Figure 1. Pigmented macules in a 23-year-old female with NF-1. Café-au-lait spots are very developed in the abdomen. This clinical sign which is a cutaneous hyperpigmentation is essential for the diagnosis of neurofibromatosis (blue arrow). (a) The orofacial skin is affected mainly by freckles and smaller café-au-lait spots. This clinical feature of neurofibromatosis is frequently present on patient's faces (blue arrow). (b) Neurofibromas may be seen in this area (black arrow). 
addition to these pigmentations tumors called neurofibromas are common. Orofacial skin may also be affected by cutaneous neurofibromas (Figure 1(b)). These are benign tumors located on the peripheral nerves and composed of a variety of cell types. They are classified as five subtypes by the World Health Organization (WHO): localized cutaneous, localized intraneural, plexiform, diffuse cutaneous, and soft tissue neurofibromas. Simply put, there are well-defined localized neurofibromas, diffuse neurofibromas and plexiform neurofibromas whose prognosis is more uncertain. Neurofibromas is constituted by Schwann cells, nerve fibers, mast cells and fibroblasts (perineural and endoneuria) in a myxoid matrix [30]. The presence of multiple neurofibromas is one of the features of NF-1 disease. They are rarely present at birth but appear in early childhood and adolescence. Their quantity increases with age and varies from one individual to another. Patients have been found with up to several thousand tumors. Several studies have shown an increase in the volume and number of tumors during puberty and pregnancy [31] [32]. The most common location is skin, though many organs may be involved, such as the larynx, stomach, intestine, kidney, bladder and heart. On the head, the most common sites are neck, scalp, cheeks and oral cavity. Neurofibromas are present in the facial area in $25 \%$ of NF-1 patients, and in the oral cavity in $6.5 \%$ of patients [33]. Hyperpigmentation of the mucous membranes and neurofibromas are often associated with pathologies of the oral mucosa.

\section{Oral Mucosal Pathology}

NF-1 oral mucosal pathology is defined by the presence of soft tissue tumor (Figure 2 and Figure 3). In the oral cavity, nodular neurofibromas of the tongue are most common [34]. There, they lead to macroglossia and enlargement of the fungiform papillae [26] [35] [36]. These benign tumors may also be located on the palate [37], lips [38] and floor of the mouth [38]. Plexiform neurofibromas, which can be considered a diagnostic criterion for NF-1, are rarely located in the oral cavity [30]. They are tumors that extend along the nerves and may encompass multiple nerve branches. They can be superficial or deep and are a major complication of NF-1 due to the deformities and disability they cause. Plexiform neurofibromas may develop into a malignant peripheral nerve sheat tumor which is a highly fatal metastatic cancer. The risk of malignant transformation is estimated between $8 \%$ and $13 \%$ [39]. In the mouth, fast growth of the tumor may lead to dysphagia and respiratory distress [40]. The treatment is surgery with a possibility of recurrence after the resection. There are a variety of biomarkers for the diagnosis of these oral soft tissue tumors. S-100 expression indicates Schwann cells [41], and Collagen IV and CD34 positive cells [37] aid the diagnosis. Tuj-1 indicates neuronal involvement [37]. Another biomarker is Glut-1 which marks perineurial cells [42]. Apart from the proliferative anomalies of nervous tissues, other cells can be affected by this unregulated proliferation: that are gingival fibroblasts. Like Schwann cells and melanocytes, gingival 
(a)

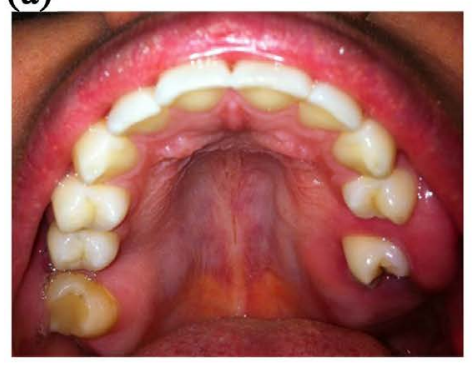

(c)

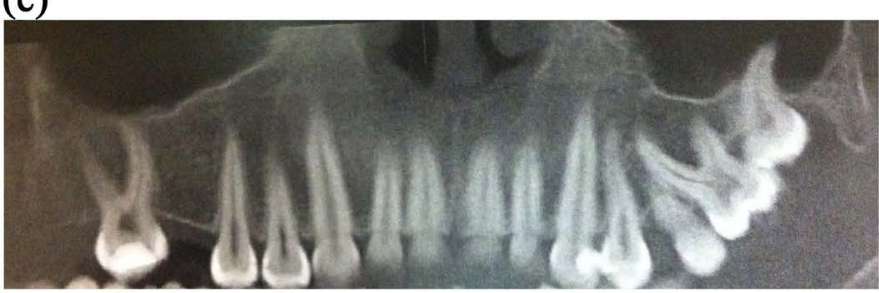

(d)

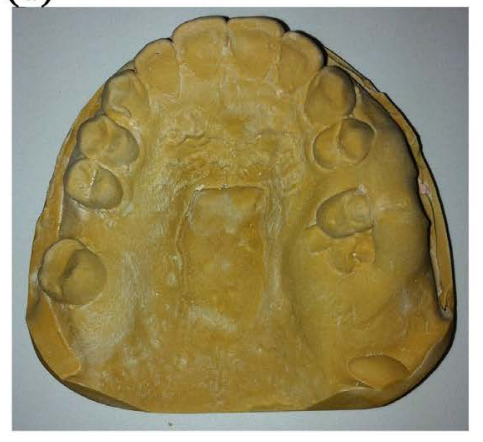

Figure 2. Damage to the maxillary area in a 23-year-old female with NF-1. The oral mucosa is prone to neurofibroma development. The development of a neurofibroma, which extends from the left vestibular maxilla mucosa through the vestibular and palatine gingiva to the palate fibromucosa ((a), (b)) in this young woman with NF1, can be linked to dental inclusions visible in X-rays (c). The bone deformation (d) is also related to this neurofibroma. The neurofibroma characteristic of the pathology is also present in the oral cavity leading to deformations of the maxillary, dental inclusions, articular and salivary pathologies.

fibroblasts derive from neural crest and may be affected by NF-1. Pathologies of the oral mucosa are frequently associated with periodontal disease.

\section{Periodontal Diseases}

Gingival thickening is widely described in patients with NF-1. The amount of gingival fibroblasts increases, along with the extracellular matrix quantity [43]. The attached gingiva is overgrown and sometimes extends to the interproximal gingiva [44]. But, this gingival swelling shows no signs of inflammation [43]. Some studies described the presence of neurofibromas in gum as $5 \%$ prevalence in NF-1 patients [26]. Fibroblasts may play a role in neurofibromas. Gingival fibroblasts have a stem cell subpopulation derived from the neural crest [45] [46]. Therefore, fibroblasts may play a role in NF1 pathology. NF-1 gingiva may exhibit 
(a)

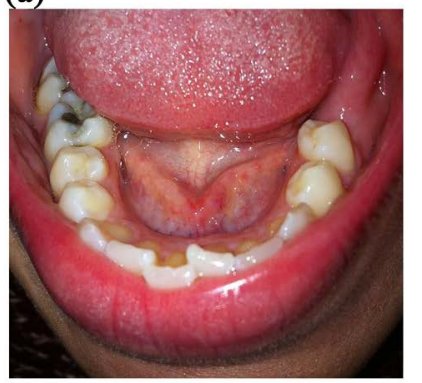

(b)

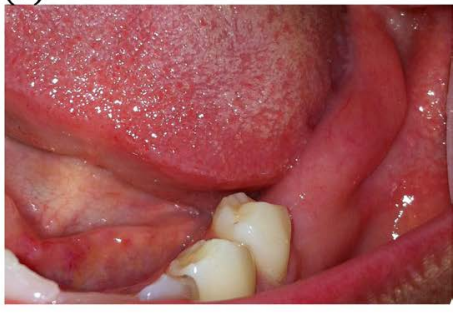

(c)

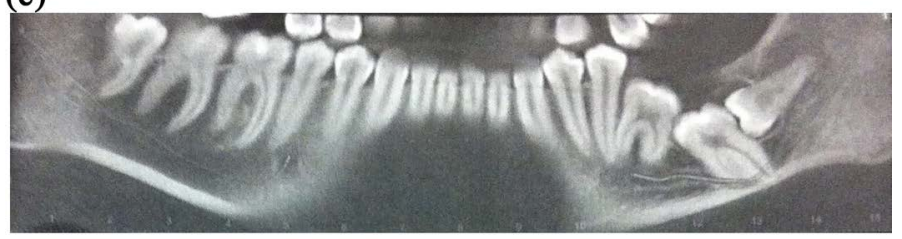

(d)

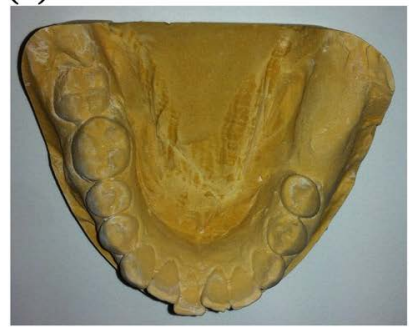

Figure 3. Damage to the mandible area in a 23-year-old female with NF-1. Neurofibromas may develop in mandible mucosa. In the case of the same patient, the neurofibroma developed from the left mandibular vestibule to the posterior buccal floor, through the mandibular crest ((a), (b)). This neurofibroma covers three molars which have undergone development issues during their maturation, as seen in the X-ray (c). Bone deformation is weakly perceived (d). As with the maxillary, the neurofibroma causes bone deformities and dental inclusions to the mandible.

pigmented macules, though it is uncommon. These appear at any age without association to race or gender [47]. These pigmentations can be a source of concern for NF-1 patients and can require an optional therapeutic treatment with a CO2 laser, for example [48] [49]. Radiographic analysis of the periodontium shows a high frequency of periapical cemental dysplasia in vital mandibular teeth of patients with NF-1 [50]. The presence of cemental dysplasia is related to gender and only concern female NF-1 patients [50]. Periodontal disease such as periodontitis may affect NF-1 patients. Periodontal attachment loss is associated with high plaque index. It is probably due to poor oral hygiene consecutive with brushing difficulties [51]. The difficulties of removing dental plaque may be due to the teeth malposition caused by jaw malformation.

\section{Jaws Lesions and Joint Diseases}

Bone lesions are also a part of the diagnostic criteria [18] [52]. However, not all NF-1 patients may develop these defects. They are more likely to develop bone manifestations than others, particularly in the facial skeleton. All of the facial 
skeleton can be affected, including the maxilla (Figure 2), mandible (Figure 3), and temporomandibular joints [53]. Jaw malformation was characterized by radiology in $28 \%$ of NF-1 patients [54]. For the mandible, the possible abnormalities include enlarged mandibular foramina [26] [54], hypoplasia of the condyle [55], elongated coronoid process, and notching in the posterior border of the ramus of mandible [56]. As for the maxilla, the zygomatic bone is hypoplasic [55]. The orbital bones may also be affected by dysplasia that often leads to a disfigurement and a narrowed maxillary sinus [57]. There is probably a common pathogenic mechanism responsible for the appearance of bone abnormalities [58]. The NF-1 gene deficiency causes increased osteoclast activity which partly explains the bone lesions [59]. In addition to the genetic etiology, local factors, due to the presence of tumors, explain bone malformations [60]. The presence of plexiform neurofibromas in the trigeminal nerve could lead to jaw malformation [60]. Friedrich et al. lead an investigation by dental panoramic X-ray on forty-eight NF patients. Twenty-nine had jaw malformation. Twenty-four among these twenty nine NF patients had plexiform neurofibromas on the same side of the malformation [60]. As for the temporo-mandibular joints, they are rarely affected by deformities [53]. But the presence of neurofibromas in the location would cause a deformation. A case of neurofibromas in the articular disc of the temporomandibular joint has been reported as causing facial asymmetry and pain [61]. In view of these bone deformations, the teeth, which are formed inside the jaws, can also be affected during their development. Thus dental abnormalities and caries are described by many authors.

\section{Dental Abnormalities and Caries}

Many studies described abnormalities in the number of teeth (agenesis, supernumerary teeth), displaced teeth and impacted teeth [54] [60] (Figure 4). This may be explained by jaw alteration, which can be related to neurofibromas (Figure 2 and Figure 3). Indeed, impacted teeth be present in the tumorous side. Facial plexiform neurofibromas may be associated with maxilla and mandible bone alteration, causing severe disfigurement [57]. The presence of plexiform neurofibromas in the oral cavity of NF-1 patients may have an impact on the size of the tooth crown [62]. It has been described that plexiform neurofibromas

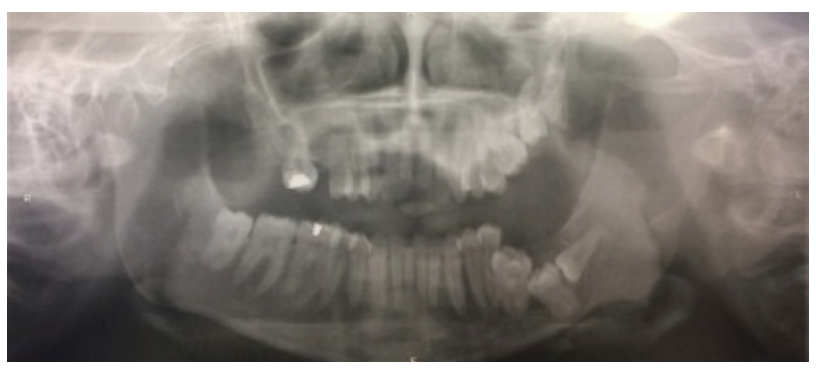

Figure 4. Dental X-ray panoramic of a 23-year-old female with NF-1. Multiple dental inclusion is highlighted. For this patient the dental inclusions are mainly at the level of mandibular and maxillary molars. 
may be associated with aplasia of the mandibular second molar, which increases teeth and jaw asymmetries in NF-1 patients [60] [62]. Also, rotated teeth were found more in NF patients than the control population. As for tooth displacement, NF patients were more affected. It was particularly maxilla lateral teeth, which were displaced into the palate side (Figure 2). The absence of second molars of patients with plexiform neurofibromas causes asymmetries that can affect the temporomandibular joint [62]. For the orthodontic abnormalities, only Class III molar occurrence is higher [34]. For children, development of primary teeth can be earlier in NF-1 patients [63]. But, another study of 34 Finnish children aged 8 to 17 years with NF-1 showed that dental development timing is not really affected by the disease [64]. As for the dental anomalies like taurodontism or enamel hypoplasia, they are noticed in NF-1 children but the prevalence of these dental anomalies is not significantly different compared to the control population [34]. So, enamel and dentin would not be affected by the disease. As for dental pulp, there is perineural fibrous thickening in NF-1 patient [65]. Also, the dental pulp stem cells of NF-1 patients have a proliferation more pronounced than the control [66].

The association between the prevalence of dental caries and neurofibromatosis type 1 is not obvious. For example, the literature shows that the incidence of dental caries is linked to brushing difficulties and poor hygiene of patients. But, dental hygiene awareness programs, implemented in different countries where the studies are carried out, are involved in the results. A Canadian retrospective study of 191 families, in which one member has NF-1, shows that the prevalence of caries was higher in patients with the disease compared to non-affected family [67]. Another Canadian study comparing children with and without NF-1 shows no significant difference in the incidence of dental caries [68]. In contrast, a Finnish study shows that for a population of NF-1 patients less than 35 years, the incidence of caries is less than the control population [69]. Displaced teeth that cause tooth brushing difficulties also promote the development of caries.

In conclusion, for dental abnormalities and caries, the prevalence of dental caries is associated with the malposition of some teeth due to the malformation of jaws often related to neurofibromas and may explain the difficulties in maintaining dental hygiene. Moreover, saliva that plays a role in the maintenance of oral homeostasis may be affected by the disease. Dental and periodontal diseases can be explained by a change in saliva,

\section{Salivary Flow}

The salivary gland, particularly the major glands, may be affected by the NF-1 pathology. Neurofibromas can develop in these glands. The most affected is the parotid [34]. It can affect adult [70] or child [71]. Plexiform neurofibromas can appear in the sublingual gland [72]. There, it is described as a kind of second tongue. The localization of the mass is not favorable because it may provoke a respiratory distress. The presence of plexiform neurofibromas is also described 
in the submandibular gland [73] [74] [75]. This gland is rarely affected by such a lesion. The salivary flow was compared between NF patients and controls. Hyposalivation affected $59 \%$ of NF-1 patient. It is described as 4 -fold higher than in the control group [76]. Saliva is a biological fluid possessing antibacterial capacity and buffer systems allowing the maintenance of a neutral $\mathrm{pH}$. So, the decrease of salivary flow would increase risk of carie development and periodontal disease such as periodontitis.

\section{Conclusion}

Oral manifestations of NF-1 patients are common due to the presence of neurofibromas in the oral cavity. These may cause bone deformities as well as macroglossia with functional and aesthetic impacts. During routine examination of NF-1 patients' oral cavity, it is important to look for neurofibromas and to make excisions when it is possible, or to monitor it to prevent a malignant degeneration. The overgrowth of neurofibromas could lead to respiratory distress in this region of the body. Moreover, in NF-1 patients, dental alignment is often disturbed by bone deformities, making oral hygiene more difficult. This is compounded by a possible hyposalivation, which accentuates the risk of developing caries and periodontal disease. The complexity of this disease, its phenotypic variation and its slow evolution make oral cavity studies difficult. But features of NF-1 summarized in this review could help prevent dental, periodontal and mucosal complications for these patients.

\section{Contributorship Statement}

HC wrote and illustrated the review, BF, AB, BM and I.-Y.S helped with writing, and $B G$ planned the study and oversaw the set.

\section{Acknowledgements}

Declared none.

\section{Conflicts of Interest}

No conflicts of interest declared.

\section{References}

[1] Riccardi, V.M. (1992) Neurofibromatosis: Phenotype, Natural History, and Pathogenesis.

[2] Gerber, P.A., Antal, A.S., Neumann, N.J., et al. (2009) Neurofibromatosis. European Journal of Medical Research, 14, 102-105.

[3] Lammert, M., Friedman, J.M., Kluwe, L., et al. (2005) Prevalence of Neurofibromatosis 1 in German Children at Elementary School Enrollment. Archives of Dermatology, 141, 71-74. https://doi.org/10.1001/archderm.141.1.71

[4] D’Ambrosio, J.A., Langlais, R.P. and Young, R.S. (1988) Jaw and Skull Changes in Neurofibromatosis. Oral Surgery, Oral Medicine, Oral Pathology, 66, 391-396. https://doi.org/10.1016/0030-4220(88)90252-6 
[5] Bottillo, I., Ahlquist, T., Brekke, H., et al. (2009) Germline and Somatic NF1 Mutations in Sporadic and NF1-Associated Malignant Peripheral Nerve Sheath Tumours. The Journal of Pathology, 217, 693-701. https://doi.org/10.1002/path.2494

[6] Eisenbarth, I., Beyer, K., Krone, W., et al. (2000) Toward a Survey of Somatic Mutation of the NF1 Gene in Benign Neurofibromas of Patients with Neurofibromatosis Type 1. American Journal of Human Genetics, 66, 393-401. https://doi.org/10.1086/302747

[7] Thomson, S.A., Fishbein, L. and Wallace, M.R. (2002) NF1 Mutations and Molecular Testing. Journal of Child Neurology, 17, 555-561. https://doi.org/10.1177/088307380201700803

[8] Daston, M.M., Scrable, H., Nordlund, M., et al. (1992) The Protein Product of the Neurofibromatosis Type 1 Gene Is Expressed at Highest Abundance in Neurons, Schwann Cells, and Oligodendrocytes. Neuron, 8, 415-428. https://doi.org/10.1016/0896-6273(92)90270-N

[9] Malhotra, R. and Ratner, N. (1994) Localization of Neurofibromin to Keratinocytes and Melanocytes in Developing Rat and Human Skin. Journal of Investigative Dermatology, 102, 812-818. https://doi.org/10.1111/1523-1747.ep12379925

[10] Gutmann, D.H., Parada, L.F., Silva, A.J., et al. (2012) Neurofibromatosis Type 1: Modeling CNS Dysfunction. Journal of Neuroscience, 32, 14087-14093. https://doi.org/10.1523/JNEUROSCI.3242-12.2012

[11] Cichowski, K. and Jacks, T. (2001) NF1 Tumor Suppressor Gene Function: Narrowing the GAP. Cell, 104, 593-604. https://doi.org/10.1016/S0092-8674(01)00245-8

[12] Cappione, A.J., French, B.L. and Skuse, G.R. (1997) A Potential Role for NF1 mRNA Editing in the Pathogenesis of NF1 Tumors. American Journal of Human Genetics, 60, 305-312.

[13] Nishi, T., Lee, P.S., Oka, K., et al. (1991) Differential Expression of Two Types of the Neurofibromatosis Type 1 (NF1) Gene Transcripts Related to Neuronal Differentiation. Oncogene, 6, 1555-1559.

[14] Bahuau, M., Vidaud, M. and Vidaud, D. (1997) Génétique et physiopathologie moléculaire. John Libbey Eurotext, 3, 623-628.

[15] Nishi, T. and Saya, H. (1991) Neurofibromatosis Type 1 (NF1) Gene: Implication in Neuroectodermal Differentiation and Genesis of Brain Tumors. Cancer and Metastasis Reviews, 10, 301-310. https://doi.org/10.1007/BF00554792

[16] Skuse, G.R. and Cappione, A.J. (1997) RNA Processing and Clinical Variability in Neurofibromatosis Type 1 (NF1). Human Molecular Genetics, 6, 1707-1712. https://doi.org/10.1093/hmg/6.10.1707

[17] National Institutes of Health Consensus Development Conference (1988) Neurofibromatosis. Conference Statement. Archives of Neurology, 45, 575-578.

[18] Gutmann, D.H., Aylsworth, A., Carey, J.C., et al. (1997) The Diagnostic Evaluation and Multidisciplinary Management of Neurofibromatosis 1 and Neurofibromatosis 2. JAMA, 278, 51-57. https://doi.org/10.1001/jama.1997.03550010065042

[19] Ferner, R.E., Huson, S.M., Thomas, N., et al. (2007) Guidelines for the Diagnosis and Management of Individuals with Neurofibromatosis 1. Journal of Medical Genetics, 44, 81-88. https://doi.org/10.1136/jmg.2006.045906

[20] Cnossen, M.H., van der Est, M.N., Breuning, M.H., et al. (1997) Deletions Spanning the Neurofibromatosis Type 1 Gene: Implications for Genotype-Phenotype Correlations in Neurofibromatosis Type 1? Human Mutation, 9, 458-464. https://doi.org/10.1002/(SICI)1098-1004(1997)9:5<458::AID-HUMU13>3.0.CO;2-1 
[21] Leppig, K.A., Kaplan, P., Viskochil, D., et al. (1997) Familial Neurofibromatosis 1 Microdeletions: Cosegregation with Distinct Facial Phenotype and Early Onset of Cutaneous Neurofibromata. American Journal of Medical Genetics, 73, 197-204. https://doi.org/10.1002/(SICI)1096-8628(1997)73:2<197::AID-AJMG17>3.0.CO;2-P

[22] De Raedt, T., Brems, H., Wolkenstein, P., et al. (2003) Elevated Risk for MPNST in NF1 Microdeletion Patients. American Journal of Human Genetics, 72, 1288-1292. https://doi.org/10.1086/374821

[23] Hyman, S.L., Shores, A. and North, K.N. (2005) The Nature and Frequency of Cognitive Deficits in Children with Neurofibromatosis Type 1. Neurology, 65, 1037-1044. https://doi.org/10.1212/01.wnl.0000179303.72345.ce

[24] Bolande, R.P. (1981) Neurofibromatosis-The Quintessential Neurocristopathy: Pathogenetic Concepts and Relationships. Advances in Neurology, 29, 67-75.

[25] Kuratani, S. (2005) Craniofacial Development and the Evolution of the Vertebrates: The Old Problems on a New Background. Zoological Science, 22, 1-19.

https://doi.org/10.2108/zsj.22.1

[26] Shapiro, S.D., Abramovitch, K., Van Dis, M.L., et al. (1984) Neurofibromatosis: Oral and Radiographic Manifestations. Oral Surgery, Oral Medicine, Oral Pathology, 58, 493-498. https://doi.org/10.1016/0030-4220(84)90350-5

[27] Jimbow, K., Szabo, G. and Fitzpatrick, T.B. (1973) Ultrastructure of Giant Pigment Granules (Macromelanosomes) in the Cutaneous Pigmented Macules of Neurofibromatosis. Journal of Investigative Dermatology, 61, 300-309. https://doi.org/10.1111/1523-1747.ep12676518

[28] Martuza, R.L., Philippe, I., Fitzpatrick, T.B., et al. (1985) Melanin Macroglobules as a Cellular Marker of Neurofibromatosis: A Quantitative Study. Journal of Investigative Dermatology, 85, 347-350. https://doi.org/10.1111/1523-1747.ep12276952

[29] De Schepper, S., Boucneau, J., Lambert, J., et al. (2005) Pigment Cell-Related Manifestations in Neurofibromatosis Type 1: An Overview. Pigment Cell Research, 18, 13-24. https://doi.org/10.1111/j.1600-0749.2004.00206.x

[30] Kamra, H.T., Dantkale, S.S., Birla, K., et al. (2013) Plexiform Neurofibroma in the Submandibular Gland Along with Small Diffuse Neurofibroma in the Floor of the Mouth But without Neurofibromatosis-1: A Rare Case Report. Ecancermedicalscience, 7,313

[31] Dugoff, L. and Sujansky, E. (1996) Neurofibromatosis Type 1 and Pregnancy. American Journal of Medical Genetics, 66, 7-10. https://doi.org/10.1002/(SICI)1096-8628(19961202)66:1<7::AID-AJMG2>3.0.CO;2R

[32] Cunha, K.S., Barboza, E.P. and Da Fonseca, E.C. (2003) Identification of Growth Hormone Receptor in Localised Neurofibromas of Patients with Neurofibromatosis Type 1. Journal of Clinical Pathology, 56, 758-763. https://doi.org/10.1136/jcp.56.10.758

[33] Marocchio, L.S., Oliveira, D.T., Pereira, M.C., et al. (2007) Sporadic and Multiple Neurofibromas in the Head and Neck Region: A Retrospective Study of 33 Years. Clinical Oral Investigations, 11, 165-169. https://doi.org/10.1007/s00784-006-0096-6

[34] Bardellini, E., Amadori, F., Flocchini, P., et al. (2011) Oral Findings in 50 Children with Neurofibromatosis Type 1. A Case Control Study. European Journal of Paediatric Dentistry, 12, 256-260.

[35] Kumar, D. (2008) Disorders of the Genome Architecture: A Review. Genome Medi- 
cine, 2, 69-76. https://doi.org/10.1007/s11568-009-9028-2

[36] Bongiorno, M.R., Pistone, G. and Arico, M. (2006) Manifestations of the Tongue in Neurofibromatosis Type 1. Oral Diseases, 12, 125-129.

https://doi.org/10.1111/j.1601-0825.2005.01168.x

[37] Jouhilahti, E.M., Visnapuu, V., Soukka, T., et al. (2012) Oral Soft Tissue Alterations in Patients with Neurofibromatosis. Clinical Oral Investigations, 16, 551-558. https://doi.org/10.1007/s00784-011-0519-x

[38] Maruyama, M., Fushiki, H. and Watanabe, Y. (2011) Solitary Neurofibroma of the Floor of the Mouth: A Case Report. Case Reports in Otolaryngology, 2011, Article ID: 967896. https://doi.org/10.1155/2011/967896

[39] Evans, D.G., Baser, M.E., McGaughran, J., et al. (2002) Malignant Peripheral Nerve Sheath Tumours in Neurofibromatosis 1. Journal of Medical Genetics, 39, 311-314. https://doi.org/10.1136/jmg.39.5.311

[40] Ozturk, O. and Tutkun, A. (2012) A Case Report of a Malignant Peripheral Nerve Sheath Tumor of the Oral Cavity in Neurofibromatosis Type 1. Case Reports in Otolaryngology, 2012, Article ID: 936735.

[41] Weiss, S.W., Langloss, J.M. and Enzinger, F.M. (1983) Value of S-100 Protein in the Diagnosis of Soft Tissue Tumors with Particular Reference to Benign and Malignant Schwann Cell Tumors. Laboratory Investigation, 49, 299-308.

[42] Hirose, T., Tani, T., Shimada, T., et al. (2003) Immunohistochemical Demonstration of EMA/Glut1-Positive Perineurial Cells and CD34-Positive Fibroblastic Cells in Peripheral Nerve Sheath Tumors. Modern Pathology, 16, 293-298. https://doi.org/10.1097/01.MP.0000062654.83617.B7

[43] Mahajan, A., Dixit, J. and Bhardwaj, A. (2010) Gingival Enlargement in Neurofibromatosis Type 1: A Case Report and Literature Review. The Journal of Contemporary Dental Practice, 11, 57-63.

[44] Shetty, B., Umesh, Y., Kranti, K., et al. (2013) Periodontal Manifestations of Von Recklinghausen Neuro Fibromatosis. Journal of Indian Society of Periodontology, 17, 253-256. https://doi.org/10.4103/0972-124X.113092

[45] Fournier, B.P., Ferre, F.C., Couty, L., et al. (2010) Multipotent Progenitor Cells in Gingival Connective Tissue. Tissue Engineering Part A, 16, 2891-2899. https://doi.org/10.1089/ten.tea.2009.0796

[46] Hakkinen, L., Larjava, H. and Fournier, B.P. (2014) Distinct Phenotype and Therapeutic Potential of Gingival Fibroblasts. Cytotherapy, 16, 1171-1186. https://doi.org/10.1016/j.jcyt.2014.04.004

[47] Ozbayrak, S., Dumlu, A. and Ercalik-Yalcinkaya, S. (2000) Treatment of Melanin-Pigmented Gingiva and Oral Mucosa by $\mathrm{CO}_{2}$ Laser. Oral Surgery, Oral Medicine, Oral Pathology, Oral Radiology, 90, 14-15. https://doi.org/10.1067/moe.2000.106396

[48] Yeh, C.J. (1998) Cryosurgical Treatment of Melanin-Pigmented Gingiva. Oral Surgery, Oral Medicine, Oral Pathology, Oral Radiology, 86, 660-663. https://doi.org/10.1016/S1079-2104(98)90199-8

[49] Almas, K. and Sadig, W. (2002) Surgical Treatment of Melanin-Pigmented Gingiva; an Esthetic Approach. Indian Journal of Dental Research, 13, 70-73.

[50] Visnapuu, V., Peltonen, S., Ellila, T., et al. (2007) Periapical Cemental Dysplasia Is Common in Women with NF1. European Journal of Medical Genetics, 50, 274-280. https://doi.org/10.1016/j.ejmg.2007.04.001

[51] Doufexi, A., Mina, M. and Ioannidou, E. (2005) Gingival Overgrowth in Children: 
Epidemiology, Pathogenesis, and Complications. A Literature Review. Journal of Periodontology, 76, 3-10. https://doi.org/10.1902/jop.2005.76.1.3

[52] Muller, H. and Slootweg, P.J. (1981) Maxillofacial Deformities in Neurofibromatosis. Journal of Maxillofacial Surgery, 9, 89-95. https://doi.org/10.1016/S0301-0503(81)80022-7

[53] Lorson, E.L., DeLong, P.E., Osbon, D.B., et al. (1977) Neurofibromatosis with Central Neurofibroma of the Mandible: Review of the Literature and Report of Case. The Journal of Oral Surgery, 35, 733-738.

[54] Visnapuu, V., Peltonen, S., Tammisalo, T., et al. (2012) Radiographic Findings in the Jaws of Patients with Neurofibromatosis 1. Journal of Oral and Maxillofacial Surgery, 70, 1351-1357. https://doi.org/10.1016/j.joms.2011.06.204

[55] Avcu, N., Kansu, O., Uysal, S., et al. (2009) Cranio-Orbital-Temporal Neurofibromatosis with Cerebral Hemiatrophy Presenting as an Intraoral Mass: A Case Report. Journal of the California Dental Association, 37, 119-121.

[56] Krishnamoorthy, B., Singh, P., Gundareddy, S.N., et al. (2013) Notching in the Posterior Border of the Ramus of Mandible in a Patient with Neurofibromatosis Type I-A Case Report. Journal of Clinical and Diagnostic Research, 7, 2390-2391. https://doi.org/10.7860/JCDR/2013/5952.3534

[57] Friedrich, R.E., Stelljes, C., Hagel, C., et al. (2010) Dysplasia of the Orbit and Adjacent Bone Associated with Plexiform Neurofibroma and Ocular Disease in 42 NF-1 Patients. Anticancer Research, 30, 1751-1764.

[58] Alwan, S., Armstrong, L., Joe, H., et al. (2007) Associations of Osseous Abnormalities in Neurofibromatosis 1. American Journal of Medical Genetics Part A, 143, 1326-1333. https://doi.org/10.1002/ajmg.a.31754

[59] Stevenson, D.A., Yan, J., He, Y., et al. (2011) Multiple Increased Osteoclast Functions in Individuals with Neurofibromatosis Type 1. American Journal of Medical Genetics Part A, 155, 1050-1059. https://doi.org/10.1002/ajmg.a.33965

[60] Friedrich, R.E., Giese, M., Schmelzle, R., et al. (2003) Jaw Malformations plus Displacement and Numerical Aberrations of Teeth in Neurofibromatosis Type 1: A Descriptive Analysis of 48 Patients Based on Panoramic Radiographs and Oral Findings. Journal of Cranio-Maxillofacial Surgery, 31, 1-9. https://doi.org/10.1016/S1010-5182(02)00160-9

[61] Van Damme, P.A., Freihofer, H.P. and De Wilde, P.C. (1996) Neurofibroma in the Articular Disc of the Temporomandibular Joint: A Case Report. Journal of Cranio-Maxillofacial Surgery, 24, 310-313. https://doi.org/10.1016/S1010-5182(96)80065-5

[62] Friedrich, R.E., Giese, M., Stelljes, C., et al. (2012) Size of Tooth Crowns and Position of Teeth Concerning the Extension of Facial Plexiform Neurofibroma in $\mathrm{Pa}$ tients with Neurofibromatosis Type 1. Anticancer Research, 32, 2207-2214.

[63] Lammert, M., Friedrich, R.E., Friedman, J.M., et al. (2007) Early Primary Tooth Eruption in Neurofibromatosis 1 Individuals. European Journal of Oral Sciences, 115, 425-426. https://doi.org/10.1111/j.1600-0722.2007.00474.x

[64] Jaasaari, P., Visnapuu, V., Nystrom, M., et al. (2012) Dental Age in Patients with Neurofibromatosis 1. European Journal of Oral Sciences, 120, 549-552. https://doi.org/10.1111/j.1600-0722.2012.01000.x

[65] Curtin, J.P. and McCarthy, S.W. (1997) Perineural Fibrous Thickening within the Dental Pulp in Type 1 Neurofibromatosis: A Case Report. Oral Surgery, Oral Medicine, Oral Pathology, Oral Radiology, 84, 400-403. https://doi.org/10.1016/S1079-2104(97)90038-X 
[66] Almeida, P.N., Souza, G.T., de Souza, C.M., et al. (2015) Proposing the Use of Dental Pulp Stem Cells as a Suitable Biological Model of Neurofibromatosis Type 1. Child s Nervous System, 31, 7-13. https://doi.org/10.1007/s00381-014-2599-9

[67] Tucker, T., Birch, P., Savoy, D.M., et al. (2007) Increased Dental Caries in People with Neurofibromatosis 1. Clinical Genetics, 72, 524-527. https://doi.org/10.1111/j.1399-0004.2007.00886.x

[68] Tsang, E.S., Birch, P., Friedman, J.M., et al. (2010) Prevalence of Dental Caries in Children with Neurofibromatosis 1. Clinical Oral Investigations, 14, 479-480. https://doi.org/10.1007/s00784-009-0361-6

[69] Visnapuu, V., Pienihakkinen, K., Peltonen, S., et al. (2011) Neurofibromatosis 1 and Dental Caries. Clinical Oral Investigations, 15, 119-121. https://doi.org/10.1007/s00784-009-0341-x

[70] Malcolm, E.K. and Lopes, M.B. (2002) April 2002: 35-Year-Old Healthy Man with Enlarging Right Parotid Mass. Brain Pathology, 12, 515-621.

[71] Thompson, M., Cheng, L.H., Stewart, J., et al. (2004) A Paediatric Case of a Solitary Fibrous Tumour of the Parotid Gland. International Journal of Pediatric Otorhinolaryngology, 68, 481-487. https://doi.org/10.1016/j.ijporl.2003.10.023

[72] Yamada, N., Uchinuma, E., Shioya, N., et al. (1992) Plexiform Neurofibromatosis in an Infant. British Journal of Plastic Surgery, 45, 175-176. https://doi.org/10.1016/0007-1226(92)90182-W

[73] Derekoy, S. and Sefali, M. (2000) Plexiform Neurofibroma of the Submandibular Gland. The Journal of Laryngology \& Otology, 114, 643-645. https://doi.org/10.1258/0022215001906390

[74] Aribandi, M., Wood, W.E., Elston, D.M., et al. (2006) CT Features of Plexiform Neurofibroma of the Submandibular Gland. American Journal of Neuroradiology, 27, 126-128.

[75] Tsutsumi, T., Oku, T. and Komatsuzaki, A. (1996) Solitary Plexiform Neurofibroma of the Submandibular Salivary Gland. The Journal of Laryngology \& Otology, 110, 1173-1175. https://doi.org/10.1017/S0022215100136072

[76] Cunha, K.S., Rozza-de-Menezes, R.E., Luna, E.B., et al. (2015) High Prevalence of Hyposalivation in Individuals with Neurofibromatosis 1: A Case-Control Study. Orphanet Journal of Rare Diseases, 10, 24. https://doi.org/10.1186/s13023-015-0239-4 